$\xi_{p}$

\title{
Energy Security in Malaysia: a Quantitative Analysis
}

\author{
Endang Jati Mat Sahid \\ Department of Mechanical Engineering, College of Engineering, Universiti Tenaga Nasional \\ *Corresponding Author E mail: endang@uniten.edu.my
}

\begin{abstract}
This paper examines the security of energy supply in Malaysia. Analytical framework was used to quantify and assess the progress of energy security of Malaysia in four different categories namely Availability, Applicability, Affordability and Acceptability of energy resources. Key metrics include the documentation of energy reserves, energy access, and $\mathrm{CO}_{2}$ emissions from year 2005 to 2015 . Relevant energy security indicators for Malaysia were identified using high quality historical data from World Bank and Energy Commission. The evaluation findings show that Malaysia has experienced a significant improvement in Applicability dimension, while Availability and Acceptability aspects of energy security only registered slight improvements. On the other hand, Affordability dimension has suffered a slight decline. This study suggests that diversifying energy sources, efficient utilization of energy and reducing carbon content of energy could be enhanced to improve energy security level in Malaysia.
\end{abstract}

Keywords: Energy security indicator; Energy policy; Malaysia, Security of supply

\section{Introduction}

Energy supply is imperative for economic development. Various literatures has documented that energy security is essential for sustaining economic development of any country [1], [2]. The issue of energy security has been taken seriously by policy makers around the world, such as Austria [3], United States [4], Southeast Asian region [5]-[7] and Europe [8]-[10]. For European region the main energy security agenda are diversification of energy sources and external energy dependence [8], [9]. Which is mainly due to the region's dependence on natural gas supplied from Russia. Correspondingly, Umbach F. [10] has recognized the importance of geopolitical dimension for European region's future energy security.

Similar to other countries, security of energy supply is indispensable for Malaysia's economic activity. However, energy supply security seems to be quite a challenge in the face of limited indigenous energy resource and increasing demand. At current reserve to production rate, oil and natural gas are showing signs of depletion with $\mathrm{R} / \mathrm{P}$ ratio of about 30 and 40 years respectively. On the other hand, the demand for electricity for the country is expected to double from year 2013 to 2050, increasing from 443 PJ in 2013 to $893 \mathrm{PJ}$ in 2050 [11]. In addition, environmental aspect of energy use is also a concern, this is because Malaysia has ratified to Paris Agreement to reduce $45 \%$ of green house gases (GHG) emissions by 2030 relative to 2005 levels.

The issue of energy security was studied extensively by various literatures [12]-[14]. Energy supply security can be assessed quantitatively by applying suitable energy security indicators to a set of high quality data. Extensive review of energy security indicators have been carried out by Sharifuddin [15] and Kruyt et. al. [16]. 4As framework of energy security has been widely used in energy security indicator analysis [17], [18]. In order to examine the progress of energy security in Malaysia, this paper will evaluate the energy supply security of Malaysia with regards to 4As crite- ria, namely; availability, affordability, applicability and acceptability.

This paper consists of four sections. Following this introduction, Section two describe the methodology and indicators applied to assess the energy security for Malaysia. Section three presents the results and analysis, and Section four will conclude the findings of this study.

\section{Methodology}

This study used indicator based assessment to quantify the dynamic changes of energy security in Malaysia.

\subsection{Selecting Energy Security Indicators}

The indicators used in the study has been categorised into 4 dimensions, namely Availability, Applicability, Affordability and Acceptability, i.e. 4 As. Indicator for each A-category has been selected based on their suitability and data availability.

\subsubsection{Availability Indicators (AV)}

Availability element has been applied by past researchers to evaluate energy security, such as [17]-[19]. Availability is one of the indicators for physical availability of energy supply. In this study, three availability elements has been analysed, as detailed below:

AV-1: Oil reserve-to-production $(\mathrm{R} / \mathrm{P})$ ratio

The $\mathrm{R} / \mathrm{P}$ ratio is used to assess the availability of oil resource in a country [17]. The indicator is the ratio of oil reserve remaining at the end of the year to the production of oil in that year. With the assumption that the production of oil remain constant throughout the years.

AV-2: Natural gas reserve-to-production $(\mathrm{R} / \mathrm{P})$ ratio

Similar to oil $\mathrm{R} / \mathrm{P}$ ratio, natural gas $\mathrm{R} / \mathrm{P}$ ratio will indicate the availability of natural gas reserve in the country [18]. It is calcu- 
lated by dividing natural gas reserve remaining at the end of the year with natural gas production in that particular year, assuming that the production remain constant.

AV-3: Coal import dependency ratio

Malaysia has been highly dependent on imported coal, particularly for its power generation sector [20]. Energy import dependency ratio is one of the indicators used to measure the security of energy supply [18]. This indicator is used to check how dependent Malaysia is on foreign supply of coal. This indicator is the ratio of net coal import to gross coal primary consumption, which indicates lower energy security at higher raw value. Therefore, inverse normalization methods is applied to the ordinal value.

\subsubsection{Applicability Indicators (AP)}

Applicability element has been widely used to evaluate energy security [17], [18], [21]. Similar to availability element, Applicability is used to indicate the physical security of energy supply with an added dimension that is, efficiency aspects of energy utilization. In this study two applicability indicators was examine, as detailed below:

AP-1: Energy supply intensity (toe/GDP at 2010 prices, RM million)

This indicator will depict the extent of deployment of energy efficient technology [18]. This indicator measures the amount energy resources needed to produce a unit of gross domestic product (GDP).

AP-2: Energy consumption intensity (toe/GDP at 2010 prices, RM million)

Similar to AP-1, this indicator will measure the extent of penetration of energy efficient technology at demand-side. This indicator is the ratio of total final energy demand to GDP at constant 2010 prices.

\subsubsection{Affordability Indicators (AF)}

Affordability indicators dealt with the economic security, the indicators are used to reveal whether or not the population can afford to pay for the energy consumed. In this study three affordability elements has been analysed, as detailed below:

AF-1: Energy consumption per capita (toe per person)

This indicator will indirectly reveal whether or not the price of energy is affordable to the population [18]. The indicator is calculated by dividing the total primary energy supply the total number of population.

AF-2: Gasoline price volatility.

Gasoline price volatility is used to indicate the price of the petroleum product. Ex-Singapore prices of gasoline was used in order to reflect the market price of gasoline.

AF-3: Electricity Tariff

This indicator is used to reveal the affordability of electricity to the population [17]. Average electricity tariff for Peninsular Malaysia was applied in this study.

\subsubsection{Acceptability Indicators (AC)}

Acceptability indicators are used to measure environmental and social elements of energy security [16]. In this study, three Acceptability elements have been examined, as detailed below:

AC-1: $\mathrm{CO}_{2}$ emissions per capita

This indicator has been widely used to measure acceptability dimension of energy security [5], [15], [17], [19], [22]. It is calculated by dividing the total $\mathrm{CO}_{2}$ emission to the total number of population. The higher normalised score reflect the higher social acceptance of the impacts of the energy used.

AC-2: Renewable energy output

Renewable energy output indicator is the share of renewable energy output out of the total electricity generation.

The indicators used in this study are summarized in Table 1 below.
Table 1: Indicators under each category

\begin{tabular}{|c|c|c|}
\hline Element & Indicator & Code \\
\hline & R/P Ratio of Oil & AV-1 \\
\hline Availability & R/P Ratio of NG & AV-2 \\
\hline \multirow{2}{*}{ Applicability } & Coal Import Dependency Ratio & AV-3 \\
\cline { 2 - 3 } & Energy Supply Intensity & AP-1 \\
\hline \multirow{3}{*}{ Affordability } & Electricity Consumption Intensity & AP-2 \\
\cline { 2 - 3 } & Energy Consumption per Capita & AF-1 \\
\cline { 2 - 3 } & Gasoline Price Volatility & AF-2 \\
\hline \multirow{2}{*}{ Acceptability } & Electricity tariff & AF-3 \\
\cline { 2 - 3 } & $\mathrm{CO}_{2}$ Emission per Capita & AC-1 \\
\hline
\end{tabular}

\subsection{Data}

The analysis was based on data from year 2005 to 2015. Primary energy data and statistics on emissions were retrieved from Energy Commissions and World Bank while macroeconomics data were retrieved from Department of Statistics. Crude-oil and natural gas-related data were gathered from BP statistical review of world energy.

\subsection{Data Normalization}

In order to make the collected data comparable, the data were normalized on the scale of ordinal values. In a range of ordinal value of $1-10$, the higher the score conveys to a better energy security performance. The scoring throughout the years under review will reflect the dynamic changes of energy security status of Malaysia.

The data normalization formula used by Tongsopit et. al. [17] was applied in this study.

$\mathrm{X}^{\prime}=1+\left(\mathrm{X}-\mathrm{Min}_{\mathrm{A}}\right)(10-1) /\left(\operatorname{Max}_{\mathrm{A}}-\mathrm{Min}_{\mathrm{A}}\right)$

Where;

$\mathrm{X}^{\prime}=$ Normalized value based on 1-10 scale

$\operatorname{Min}_{\mathrm{A}}=$ Minimum value of data range $\mathrm{A}$

$\operatorname{Max}_{\mathrm{A}}=$ Maximum value of data range $\mathrm{A}$

Further, for indicators that are inversely related to with the scale, i.e. higher raw value indicates lower energy security; the reverse normalization formula depicted below was used. For this case, the maximum value of the raw scare is considered as the minimum scale value which is equivalent to 1 , and vice versa.

$X^{\prime}=1+\left(X-M_{A}\right)(10-1) /\left(\operatorname{Min}_{A}-\operatorname{Max}_{A}\right)$

Where;

$\mathrm{X}^{\prime}=$ Normalized value based on 1-10 scale

$\operatorname{Min}_{\mathrm{A}}=$ Minimum value of data range $\mathrm{A}$

$\operatorname{Max}_{\mathrm{A}}=$ Maximum value of data range A

\section{Results and Analyses}

The results from the quantitative analysis depict the status of Malaysia energy security. The findings are discussed in following four sub-section, categorised by each energy security dimension.

\subsection{Availability (AV)}

Availability of Malaysian energy resources has experienced a slight improvement from 2005 to 2015, as depicted in Fig.1. The average score of Availability element increased from 4.9 in 2005 to 5.4 in 2015 . The energy resource availability had peaked in year 2007 and 2014 with average score of 7.1 and 7.0 respectively. This trend can be rationalized by analysing the detail data in Table 2. It can be seen that R/P Ratio of Oil (AV-1) has a high score in year 2007, while both R/P Ratio of Natural gas (AV-2) and Coal import dependency ratio (AV-3) have high ordinal value score in 
year 2014. Availability dimension could be improved by diversifying energy sources and efficient utilization of energy [23].

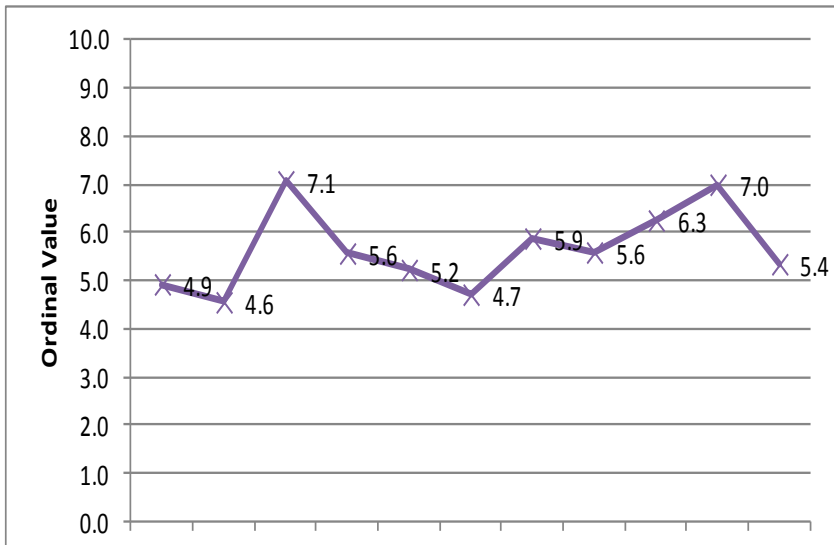

20052006200720082009201020112012201320142015

$\therefore$ Availability Element

Fig. 1: Availability metric for Malaysia from 2005 to 2015

Table 2: Normalized data for availability element

\begin{tabular}{|c|c|c|c|c|}
\hline \multirow{2}{*}{ Year } & \multicolumn{3}{|c|}{ Indicator (Code) } & \multirow{2}{*}{$\begin{array}{c}\text { Availability aver- } \\
\text { age value }\end{array}$} \\
\cline { 2 - 4 } & $\mathbf{A V - 1}$ & $\mathbf{A V - 2}$ & $\mathbf{A V - 3}$ & 4.9 \\
\hline 2005 & 7.8 & 1.0 & 6.0 & 4.6 \\
\hline 2006 & 10.0 & 2.7 & 1.0 & 7.1 \\
\hline 2007 & 9.4 & 4.6 & 7.2 & 5.6 \\
\hline 2008 & 9.6 & 1.9 & 5.2 & 5.2 \\
\hline 2009 & 1.1 & 4.6 & 10.0 & 4.7 \\
\hline 2010 & 1.0 & 4.4 & 8.8 & 5.9 \\
\hline 2011 & 2.8 & 6.5 & 8.3 & 5.6 \\
\hline 2012 & 2.4 & 5.6 & 8.8 & 6.3 \\
\hline 2013 & 4.0 & 6.8 & 7.9 & 7.0 \\
\hline 2014 & 2.4 & 10.0 & 8.6 & 5.4 \\
\hline 2015 & 1.0 & 7.5 & 7.5 & \\
\hline
\end{tabular}

\subsection{Applicability (AP)}

Malaysia saw an improvement in Applicability element of energy security from 2005 to 2015, as shown in Fig.2. The average score of Applicability element increased from 4.2 in 2005 to 7.7 in 2015. However, the energy resource applicability has dip in year 2013 a low of 2.6 ordinal values. This trend can be seen by examining the detail data in Table 3. It can be seen that Electricity consumption intensity (AP-2) has the lowest score of 1 ordinal value in year 2014. Applicability dimension could be further improved by increasing the efficiency of energy utilization [23].

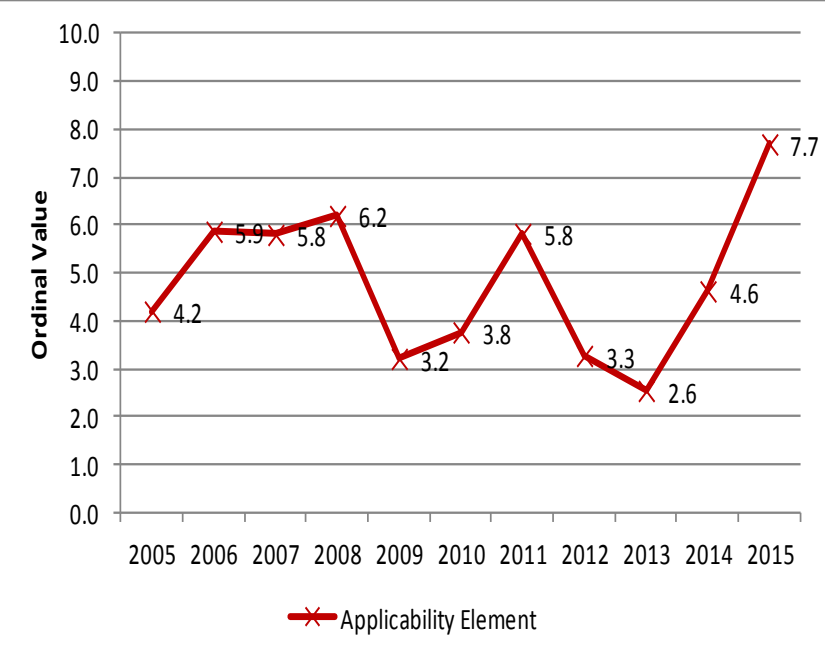

Fig. 2: Applicability metric for Malaysia from 2005 to 2015
Table 3: Normalized data for applicability element

\begin{tabular}{|c|c|c|c|}
\hline \multirow{2}{*}{ Year } & \multicolumn{2}{|c|}{ Indicator (Code) } & $\begin{array}{c}\text { Applicability average } \\
\text { value }\end{array}$ \\
\cline { 2 - 3 } & AP-1 & AP-2 & 4.2 \\
\hline 2005 & 1.0 & 7.4 & 5.9 \\
\hline 2006 & 3.4 & 8.3 & 5.8 \\
\hline 2007 & 2.5 & 9.1 & 6.2 \\
\hline 2008 & 2.4 & 10.0 & 3.2 \\
\hline 2009 & 2.6 & 3.8 & 3.8 \\
\hline 2010 & 5.0 & 2.6 & 5.8 \\
\hline 2011 & 6.0 & 5.6 & 3.3 \\
\hline 2012 & 4.2 & 2.3 & 2.6 \\
\hline 2013 & 4.1 & 1.0 & 4.6 \\
\hline 2014 & 6.2 & 3.0 & 7.7 \\
\hline 2015 & 10.0 & 5.4 & \\
\hline
\end{tabular}

\subsection{Affordability (AF)}

Affordability of Malaysian energy resources has decreased from 2005 to 2015, as depicted in Fig.3. The average score of Affordability element decreased from 6.4 in 2005 to 5.5 in 2015 . The energy resource Affordability was the lowest in 2011 with average score of 3.2. This can be further analysed looking at the detail data in Table 4. It can be seen that Gasoline price volatility (AF-2) has the lowest ordinal score in year 2011, which implies that the actual price of gasoline was the highest in that year. In addition, the steady reduction of ordinal score for Electricity Tariff (AF-3) indicates that the electricity tariff has been increasing each year from 2005 through to 2015.

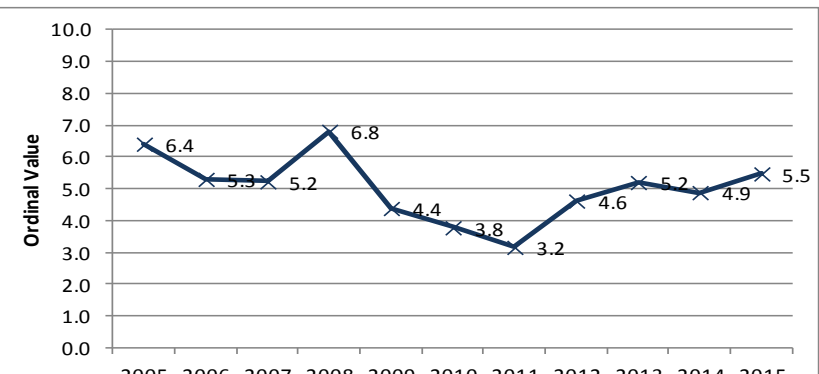

* Affordability element

Fig. 3: Affordability metric for Malaysia from 2005 to 2015

Table 4: Normalized data for affordability element

\begin{tabular}{|c|c|c|c|c|}
\hline \multirow{2}{*}{ Year } & \multicolumn{3}{|c|}{ Indicator (Code) } & \multirow{2}{*}{$\begin{array}{c}\text { Affordability aver- } \\
\text { age value }\end{array}$} \\
\cline { 2 - 4 } & $\mathbf{A F}-\mathbf{1}$ & $\mathbf{A F}-\mathbf{2}$ & $\mathbf{A F}-3$ & 6.4 \\
\hline 2005 & 1.7 & 7.5 & 10.0 & 5.3 \\
\hline 2006 & 1.0 & 6.4 & 8.5 & 5.2 \\
\hline 2007 & 4.1 & 3.0 & 8.5 & 6.8 \\
\hline 2008 & 3.4 & 10.0 & 7.0 & 4.4 \\
\hline 2009 & 1.0 & 6.7 & 5.5 & 3.8 \\
\hline 2010 & 1.0 & 4.7 & 5.6 & 3.2 \\
\hline 2011 & 2.7 & 1.4 & 5.4 & 4.6 \\
\hline 2012 & 8.6 & 1.0 & 4.2 & 5.2 \\
\hline 2013 & 10.0 & 1.5 & 4.1 & 4.9 \\
\hline 2014 & 10.0 & 2.3 & 2.3 & 5.5 \\
\hline 2015 & 8.6 & 6.8 & 1.0 & \\
\hline
\end{tabular}

\subsection{Acceptability (AC)}

Malaysia saw a slight improvement in Acceptability element of energy security from 2005 to 2015, as shown in Fig.4. The average score of Acceptability element increased from 5.2 in 2005 to 5.5 in 2015 . However, the energy resource Acceptability has dip in year 2010 to a low of 2.4 ordinal values. This trend can be examining the disaggregated data in Table 5. It can be seen that Renewable energy output (AC-2) has the lowest score of 1 ordinal value in year 2010. The Acceptability dimension could be improved by reducing carbon content of energy, facilitating lowcarbon industries and diversification of energy source, i.e. further deployment of renewable energy sources [23]. 


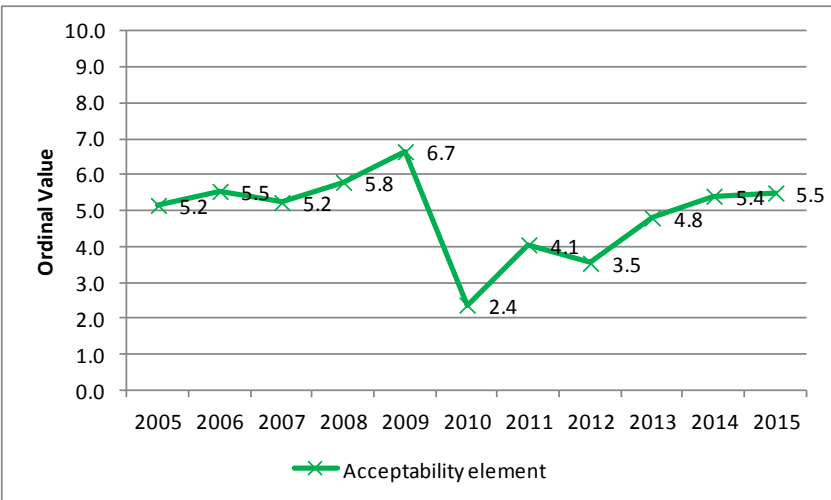

Fig. 4: Acceptability metric for Malaysia from 2005 to 2015

Table 5: Normalized data for acceptability element

\begin{tabular}{|c|c|c|c|}
\hline \multirow{2}{*}{ Year } & \multicolumn{2}{|c|}{ Indicator (Code) } & $\begin{array}{c}\text { Acceptability average } \\
\text { value }\end{array}$ \\
\cline { 2 - 3 } & AC-1 & AC-2 & 5.2 \\
\hline 2005 & 8.7 & 1.7 & 5.5 \\
\hline 2006 & 7.4 & 3.7 & 5.2 \\
\hline 2007 & 8.0 & 2.5 & 5.8 \\
\hline 2008 & 6.9 & 4.7 & 6.7 \\
\hline 2009 & 10.0 & 3.0 & 2.4 \\
\hline 2010 & 3.8 & 1.0 & 4.1 \\
\hline 2011 & 5.5 & 2.6 & 3.5 \\
\hline 2012 & 2.9 & 4.2 & 4.8 \\
\hline 2013 & 2.7 & 6.9 & 5.4 \\
\hline 2014 & 1.4 & 9.4 & 5.5 \\
\hline 2015 & 1.0 & 10.0 & \\
\hline
\end{tabular}

\section{Conclusion}

The assessment of Malaysia energy security using indicator analysis has been presented in Section 3 above. The analysis used 10 individual indicators to quantitatively measure four aspects of energy security, namely Availability, Applicability, Affordability and Acceptability. Based on the evaluation, the energy security performance of Malaysia has improved for all aspects of energy security except for Affordability. This paper suggests that energy security level of Malaysia could be enhanced by diversifying energy sources, efficient utilization of energy and reducing carbon content of energy. This paper provides a preliminary analysis of energy supply security progress in Malaysia, future research could be done to carry out more in-depth review on each energy security dimension.

\section{References}

[1] Blum, H., Legey, L.F.L. (2012). The challenging economics of energy security: Ensuring energy benefits in support to sustainable development. Energy Economics, Vol. 34, pp.1982-1989.

[2] Yoo, S-H (2006). The causal relationship between electricity consumption and economic growth in the ASEAN countries. Energy Policy, Vol. 34, pp. 3573-3582.

[3] Reichl, J., Schmidthaler, M. and Schneider, F. (2013). The value of supply security: The costs of power outages to Austrian households, firms and the public sector. Energy Economics, Vol.36, pp. 256-261.

[4] Manley, D.K., Hines, V.A., Jordan, M.W. and Stoltz, R.E. (2013). A survey of energy policy priorities in the United States: Energy supply security, economics, and the environment. Energy Policy, Vol. 60, pp. 687-696.

[5] Kanchana, K. and Unesaki, H. (2014). ASEAN Energy Security: An indicator-based assessment. Energy Procedia, Vol.56, pp. 163171.

[6] Sovacool, B. (2013). Assessing energy security performance in the Asia Pacific, 1990-2010. Renewable and Sustainable Energy Reviews, Vol. 17, pp. 228-247.

[7] Sahid, E.J.M., Isa, A.M., Leong, Y.P. and Shi, X. (2013b). Rationale for ASEAN Energy Market Integration (AEMI). In R. Oliver (Eds). ASEAN Energy Market Integration (AEMI): From coor- dination to integration (pp.45-88). Bangkok: ASEAN Studies Center, Chulalongkorn University.

[8] Bilgin, M. (2011). Scenarios on European energy security: Outcome of natural gas strategy in 2020. Futures, Vol. 43, pp. 10821090 .

[9] Costantini, V., Gracceva, F., Markandya, A. and Vicini, G. (2007). Security of energy supply: Comparing scenarios from a European perspective. Energy Policy, Vol. 35, pp. 210-226.

[10] Umbach, F. (2010). Global energy security and the implications for the EU. Energy Policy, Vol. 38, pp. 1229-1240.

[11] Haiges R, Wang YD, Ghoshray A \& Roskilly AP (2017), Optimization of Malaysia's power generation mix to meet the electricity demand by 2050, Energy Procedia 142, 2844-2851

[12] Matsumoto K \& Shiraki H (2018), Energy security performance in Japan under different socioeconomic and energy conditions, Renewable and Sustainable Energy Reviews 90, 391-401

[13] Mansson A, Johannson B \& Nilsson LJ (2014), Assessing energy security: An overview of commonly used methodologies, Energy $73,1-14$

[14] Cherp A\& Jewell J(2014), The concept of energy security: Beyond the four As, Energy Policy 75, 415-421

[15] Sharifuddin S (2014), Methodology for quantitatively assessing the energy security of Malaysia and other southeast Asian countries, Energy Policy 65, 564-582

[16] Kruyt B, van Vuuren DP, de Vries HJM \& Groenenberg H (2009), Indicaators for energy security, Energy Policy 37, 2166-2181

[17] Tongsopit S, Kittner N, Chang Y, Aksornkij A \& Wangjiraniran W (2016), Energy security in ASEAN: A quantitative approach for sustainable energy policy, Energy Policy 90, 60-72

[18] Yao L\& Chang Y(2014), Energy security in China: a quantitative analysis and policy implications, Energy Policy 67, 595-604

[19] Sovacool BK, Mukkherjee I, Drupady IM\& D’Agostino A (2011), Evaluating energy security performance from 1990 to 2010 for eighteen countries, Energy 36, 5846-5853

[20] Foo KH(2015), A vision on the opportunities, policies and coping strategies for energy security and green energy development in Malaysia, Renewable and Sustainable Energy Reviews 51, 1477-1498

[21] Rodanovic M, Filiponic S. \& Pavlovic D(2017), Energy security measurement- A sustainable approach, Renewable and Sustainable Energy Reviews 68, 1020-1032

[22] Winzer C(2012), Conceptualizing energy security, Energy Policy $46,36-48$

[23] Bekhet H.A. \& Sahid E.J.M, Illuminating the policies affecting energy security in Malaysia's electricity sector, International Journal of Economics and Management Engineering, Vol. 10, No. 4 (2016), pp:1240-1245 